\title{
Role of Adjuvant Chemotherapy in Pulmonary Carcinoids: An NCDB Analysis
}

\author{
ROHIT GOSAIN ${ }^{1}$, ADRIENNE GROMAN $^{2}$, SAI S. YENDAMURI ${ }^{3}$, RENUKA IYER $^{1}$ and SARBAJIT MUKHERJEE ${ }^{1}$ \\ ${ }^{1}$ Division of Hematology \& Oncology, Roswell Park Comprehensive Cancer Center, \\ University at Buffalo School of Medicine, Buffalo, NY, U.S.A.; \\ ${ }^{2}$ Division of Biostatistics, Roswell Park Comprehensive Cancer Center, \\ University at Buffalo School of Medicine, Buffalo, NY, U.S.A.; \\ ${ }^{3}$ Department of Thoracic Surgery Oncology, Roswell Park Comprehensive \\ Cancer Center, University at Buffalo School of Medicine, Buffalo, NY, U.S.A.
}

\begin{abstract}
Background/Aim: Typical carcinoids (TC) and atypical carcinoids $(A C)$ are rare diseases. A paucity of randomized studies and disagreements among various guidelines makes the management challenging. Patients and Methods: Using codes for TC (8240) and AC (8249) in the National Cancer Database (NCDB), all surgically resected cases from 2004-2014 were included to evaluate the need for adjuvant chemotherapy. Results: A total of 6,673 cases were included, $88 \%$ were TCs and 12\% were ACs. From 2004 to 2014 , the proportion of TCs went up from $1.3 \%$ to $1.8 \%$ and ACs from $0.1 \%$ to $0.3 \%$ of all lung malignancies. TC patients did well with surgery alone in all stages. AC patients with stage I [5-year overall survival (OS) - $84 \%$ vs. $52 \% ; S$ vs. $S+C T]$ and stage II disease (5-year OS - $81 \%$ vs. $55 \%$; $S$ vs. $S+C T)$ showed better OS trend with surgery alone, while stage III patients showed some benefit with the use of adjuvant chemotherapy (5-year OS - 46\% vs. 54\%; $S$ vs. $S+C T)$. These results supported the National Comprehensive Cancer Network (NCCN) guidelines. Conclusion: No benefit was seen from adjuvant chemotherapy in TCs. While the adjuvant therapy may add benefit in stage III AC, the numbers are small and did not reach statistical significance.
\end{abstract}

Neuroendocrine tumors (NETs) are a group of malignancies that originate from neuroendocrine cells in the body. Pulmonary NETs are a rare group of tumors that account for approximately $2 \%$ of all primary lung cancers (1). Most

Correspondence to: Sarbajit Mukherjee, MD, MS Assistant Professor of Oncology, Roswell Park Comprehensive Cancer Center, 665 Elm Street, Buffalo, NY 14263, U.S.A. Tel: +1 7168453099, Fax: +1 7168458935, e-mail: sarbajit.mukherjee@ roswellpark.org

Key Words: Neuroendocrine, pulmonary, carcinoids, typical, atypical, outcomes, adjuvant therapy, NCDB, NET. pulmonary NETs are low-grade typical carcinoids (TC), with rare cases of intermediate grade atypical carcinoids (AC)(2). Better diagnostic technologies and increased lung cancer screening may account, in part, for the increasing incidence of lung NETs (3).

Proper diagnosis and classification of pulmonary NETs are essential to treat these patients appropriately. The critical criterion that helps to classify pulmonary NETs is the number of mitoses per $2 \mathrm{~mm}^{2}$ of a viable area around the tumor, along with the presence or absence of necrosis $(4,5)$. TCs have less than two mitoses per $2 \mathrm{~mm}^{2}$ of a viable area of the tumor, with the absence of necrosis. ACs have 2 to 10 mitoses per $2 \mathrm{~mm}^{2}$ with the presence of necrosis. Other highgrade tumors like small cell lung carcinoma (SCLC) and large cell neuroendocrine carcinoma (LCNEC) present with an extensive degree of necrosis, have more than ten mitoses per $2 \mathrm{~mm}^{2}$ and are differentiated based on their appearance to the pathologist $(4,5)$.

Lack of randomized trials in the pulmonary NETs (TC and AC) population makes treatment challenging. Surgery is the mainstay of treatment in non-metastatic patients, with excellent outcomes. TCs have a 5-year overall survival (OS) rate of more than $90 \%$ post-surgery, while in AC, 5-year OS approximates to $70 \%$ (6). Previously, all lung NETs were treated like small cell lung cancer as there were no established guidelines from neuroendocrine specialists/ societies. Now, there are four different guidelines, and they all seem to disagree on recommendations for adjuvant therapy for ACs, especially for locally-advanced disease (2).

To help understand the role of adjuvant chemotherapy in TC and AC patients, we analyzed the National Cancer Database (NCDB) from years 2004 to 2014. The impact of adjuvant chemotherapy on OS based on pathological staging and nodal status was studied. We also attempted to evaluate if our data support the recommendations from various guidelines. 
Table I. Reported cases of TC and AC as a proportion of all NETs, NCDB 2004-2014.

\begin{tabular}{lccccccccccc}
\hline Incidence & 2004 & 2005 & 2006 & 2007 & 2008 & 2009 & 2010 & 2011 & 2012 & 2013 & 2014 \\
\hline TC (\%) & 1.3 & 1.4 & 1.4 & 1.5 & 1.5 & 1.5 & 1.6 & 1.5 & 1.6 & 1.6 & 1.8 \\
$\mathrm{AC} \mathrm{( \% )}$ & 0.1 & 0.1 & 0.1 & 0.2 & 0.2 & 0.2 & 0.2 & 0.2 & 0.2 & 0.2 & 0.3 \\
\hline
\end{tabular}

\section{Patients and Methods}

The NCDB is a hospital-based cancer registry sponsored by the American College of Surgeons and the American Cancer Society, which represents approximately $70 \%$ of all newly diagnosed cancer cases nationwide (7). Utilizing the NCDB participant user file, a retrospective analysis was performed on patients diagnosed between years 2004-2014. The histology codes for TC (8240) and AC (8249) were based on the ICD-03/WHO 2008 classification. As the research question was about adjuvant chemotherapy, the inclusion was limited to patients with localized TC and AC. Patients with metastatic disease, or patients who received neoadjuvant chemotherapy or had missing information about staging or pathologic nodal status, were excluded. Patients who had stage I, II and III disease as per the American Joint Committee on Cancer (AJCC 6th and 7th edition) guidelines and underwent surgical resection, were included. Other inclusion criteria included primary cancer diagnosis and information about both nodal status and adjuvant chemotherapy. Since we wanted to assess OS benefit from adjuvant chemotherapy based on different stages and nodal status, we further stratified the patient population by AJCC stages (I, II, III) and nodal status (positive versus negative). The following variables were utilized in the multivariable analyses to control for the confounders: age, sex, race, Charlson/Deyo comorbidity score, tumor type, treatment type, and the number of positive lymph nodes.

Long-term survival was evaluated using the Kaplan-Meier method with comparisons based on the log-rank test. Baseline characteristics and outcomes were compared between the individual groups. Statistical significance was indicated by $p$-values less than 0.05 .

The results from this NCDB retrospective review were then compared to four established national guidelines to evaluate if the results are in-line with one of the following guidelines: the National Comprehensive Cancer Network (NCCN), North American Neuroendocrine Tumor Society (NANETS), European Neuroendocrine Tumor Society (ENETS) and European Society of Medical Oncology (ESMO).

\section{Results}

Patients. The proportion of patients reported to NCDB with a diagnosis of TC was $1.4 \%$, and $\mathrm{AC}$ was $0.2 \%$ of all lung malignancies diagnosed during the entire period. Reported cases of TC rose from $1.3 \%$ in 2004 to $1.8 \%$ in 2014, while reported cases of AC, increased from $0.1 \%$ in 2004 to $0.3 \%$ in 2014. A similar increase in the incidence of pulmonary carcinoids has been documented from the Surveillance, Epidemiology, and End Results (SEER) database $(8,9)$. Table I below shows the rise in the reported proportions of TC and AC from years 2004 to 2014.
Table II. Baseline characteristics of pulmonary NET patients, NCDB 2004-2014.

\begin{tabular}{|c|c|c|c|}
\hline Variable & Node negative & Node positive & $p$-Value \\
\hline Overall count $(\%)$ & $5,654(86.9 \%)$ & $856(13.1 \%)$ & \\
\hline $\begin{array}{l}\text { Age in years, } \\
\text { median (range) }\end{array}$ & $60(18-90)$ & $57(18-86)$ & $<0.001$ \\
\hline Gender & & & 0.092 \\
\hline Male $(\%)$ & $1,689(29.9 \%)$ & $280(32.7 \%)$ & \\
\hline Female $(\%)$ & $3,965(70.1 \%)$ & $576(67.3 \%)$ & \\
\hline Race & & & 0.095 \\
\hline White $(\%)$ & $5,126(90.7 \%)$ & $761(88.9 \%)$ & \\
\hline Black (\%) & $358(6.3 \%)$ & $71(8.3 \%)$ & \\
\hline Other $(\%)$ & $170(3 \%)$ & $24(2.8 \%)$ & \\
\hline Histology & & & $<0.001$ \\
\hline $\mathrm{TC}(\%)$ & $5,122(90.6 \%)$ & $605(70.7 \%)$ & \\
\hline $\mathrm{AC}(\%)$ & $532(9.4 \%)$ & $251(29.3 \%)$ & \\
\hline AJCC analytic stage & & & $<0.001$ \\
\hline Stage I (\%) & $5,127(90.7 \%)$ & $25(2.9 \%)$ & \\
\hline Stage II $(\%)$ & $415(7.3 \%)$ & $486(56.8 \%)$ & \\
\hline Stage III (\%) & $112(2 \%)$ & $345(40.3 \%)$ & \\
\hline Chemotherapy & & & $<0.001$ \\
\hline None $(\%)$ & $5,617(99.3 \%)$ & $701(81.9 \%)$ & \\
\hline Single-agent $(\%)$ & $7(0.1 \%)$ & $3(0.4 \%)$ & \\
\hline Multi-agent (\%) & $30(0.5 \%)$ & $152(17.8 \%)$ & \\
\hline Surgical approach & & & $<0.001$ \\
\hline Lobectomy (\%) & $3,779(66.8 \%)$ & $649(75.8 \%)$ & \\
\hline Sublobar $(\%)$ & $1,514(26.8 \%)$ & $81(9.5 \%)$ & \\
\hline Pneumonectomy (\%) & $158(2.8 \%)$ & $79(9.2 \%)$ & \\
\hline Other $(\%)$ & $203(3.6 \%)$ & $47(5.5 \%)$ & \\
\hline Charlson-Deyo score* & & & 0.245 \\
\hline $0(\%)$ & $3,775(66.8$ & $649(75.8 \%)$ & \\
\hline $1(\%)$ & $1,462(25.9 \%)$ & $207(24.2 \%)$ & \\
\hline $2(\%)$ & $417(7.4 \%)$ & $54(6.3 \%)$ & \\
\hline
\end{tabular}

*Score predicting 1-year mortality for patients with comorbid conditions.

Baseline characteristics. A total of 6,673 TCs and ACs that underwent surgery and had a reported pathological nodal status were identified. Of these 5,880 (88.1\%) were TCs and 793 (11.9\%) were ACs. When we classified these patients based on pathological nodal status, 5,654 (86.9\%) patients were pathologically node-negative, while $856(13.1 \%)$ had node-positive disease. Of the 6,673 patients who underwent surgery, 6,477 (97\%) were observed post-surgery, and 196 (3\%) patients got adjuvant chemotherapy. Majority of the patients who got adjuvant chemotherapy were node-positive 
Table III. Adjusted multivariate analysis of pulmonary NET patients, comparing OS among patients, NCDB 2004-2014.

\begin{tabular}{lccr}
\hline Dependent variable & Reference variable & HR (95\%CI) & $p$-Value \\
\hline Surgery followed by adjuvant chemotherapy & Surgery alone & $1.81(1.17,2.79)$ & 0.008 \\
AC & TC & $1.87(1.40,2.50)$ & $<0.001$ \\
Node-positive & Node-negative & $1.12(0.68,1.85)$ & 0.664 \\
Female & Male & $0.70(0.54,0.90)$ & 0.006 \\
Surgery (other) & Lobectomy & $2.81(1.73,4.56)$ & $<0.001$ \\
Pneumonectomy & Lobectomy & $2.76(1.74,4.37)$ & $<0.001$ \\
Sublobar resection & Lobectomy & $1.37(0.98,1.91)$ & 0.064 \\
\hline
\end{tabular}

patients, $155(2.3 \%)$. The commonly performed surgeries amongst pulmonary NET patients were lobectomy $(66.9 \%)$, sublobar resection $(25.7 \%)$ and pneumonectomy $(3.6 \%)$. Baseline characteristics of the population are highlighted in Table II below.

Overall survival. A multivariable Cox proportional hazards model was used to identify factors associated with long-term survival. Overall survival was adjusted for gender, race, comorbidities, disease stage, nodal status, treatment facility type, and type of management (Table III). We found that in the whole study population, patients who underwent surgery alone had a better OS when compared to patients who underwent surgery followed by adjuvant chemotherapy. From a surgical standpoint, lobectomy was the most commonly performed procedure and yielded a significantly better outcome than pneumonectomy. Furthermore, male patients did significantly better when compared to their female counterparts.

Using the Kaplan-Meier method, overall survival (OS) was estimated for patients with pulmonary NETs, based on nodal status and different stages. Patients who got adjuvant chemotherapy post-surgery had significantly poor OS, regardless of the nodal status or stage (Figure 1). However, there were exceptions; patients with node-positive AC had no significant OS difference whether they received adjuvant chemotherapy or not $(p=0.5019)$. When subgroup analysis was done in different AJCC stages, adjuvant chemotherapy did not affect survival in stage I $(p=0.3078)$ and stage II $(p=0.2457)$ TC patients, along with stage II $(p=0.3394)$ and stage III $(p=0.2412)$ AC patients. Stage III TC patients as well as Stage I AC patients had worse survival with adjuvant chemotherapy $(p<0.01)$.

\section{Discussion}

NETs comprise $25 \%$ of all lung cancers, the most common being SCLC (20\%), followed by LCNEC (3\%), TC (less than $2 \%)$, and $\mathrm{AC}(0.2 \%)(10)$. TCs are more common than AC, comprising almost $90 \%$ of well-differentiated pulmonary NETs (10). However, there has been an increase in the incidence of pulmonary NETs lately $(11,12)$. Dasari et al. showed that the incidence of pulmonary carcinoids increased from 1.2 per 100,000 persons in 2002 to 1.6 per 100,000 persons in 2012 (8). We observed a similar trend in this NCDB retrospective analysis. This increase can be attributed to the advancement in radiological techniques.

Pulmonary NETs range from low-grade TC and intermediate-grade $\mathrm{AC}$ to the high-grade small cell and large cell neuroendocrine carcinoma $(13,14)$. It is crucial to make a distinction between low and intermediate-grade pulmonary NETs, given that they significantly differ in terms of prognosis. Post-surgery, TC has a 10 -year survival rate of $90 \%$, while AC has a 10-year survival rate of $60 \%$ (15). Additionally, patients with node-positive disease have inferior OS when compared to patients with node-negative disease $(16,17)$. In this retrospective analysis, node-negative patients had a 5-year OS rate of $91 \%$ with surgery alone, while in the node-positive group, the 5-year OS rate was $83 \%$.

From a management standpoint, surgery remains the mainstay of treatment for TCs and ACs. Fox et al. highlighted the conventional surgical approaches used in pulmonary NET patients, lobectomy $(1,669 ; 51.2 \%)$ being the most common, followed by sublobar resection with wedge resection or segmentectomy $(784 ; 24.1 \%)$, pneumonectomy, bronchoplasty or extended resection (18). The most common surgical approaches identified in our study were similar to what has been demonstrated before; lobectomy, followed by sublobar resection and pneumonectomy.

Management following surgery is controversial, and guidelines tend to differ. North American Neuroendocrine Tumor Society (NANETS) and European Society of Medical Oncology (ESMO) guidelines do not provide recommendations for or against adjuvant chemotherapy (19, 20). For stage I and II TC and AC patients, surgery alone is recommended by the National Comprehensive Cancer Center (NCCN) and the European Neuroendocrine Tumor Society (ENETS) guidelines $(21,22)$. However, for stage III disease, NCCN guidelines recommend surgery alone for TCs and considering adjuvant cisplatin and etoposide with or without 
A

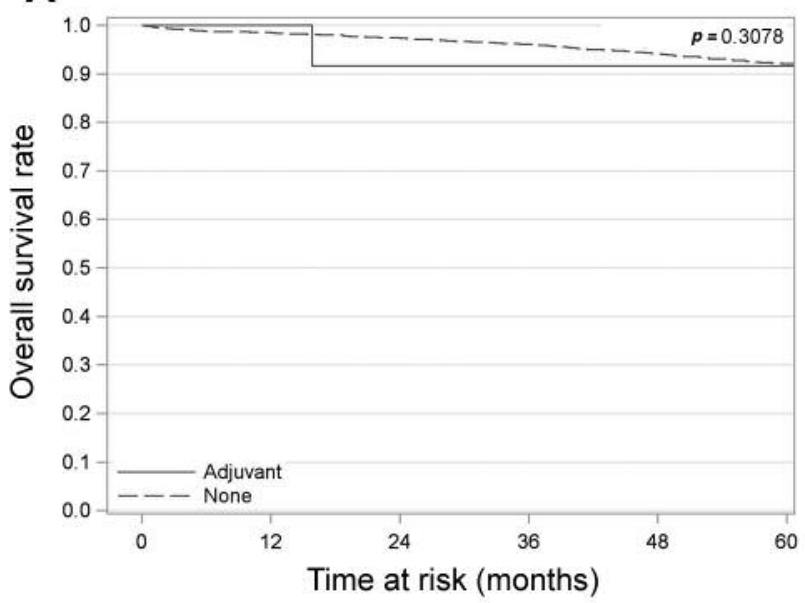

B

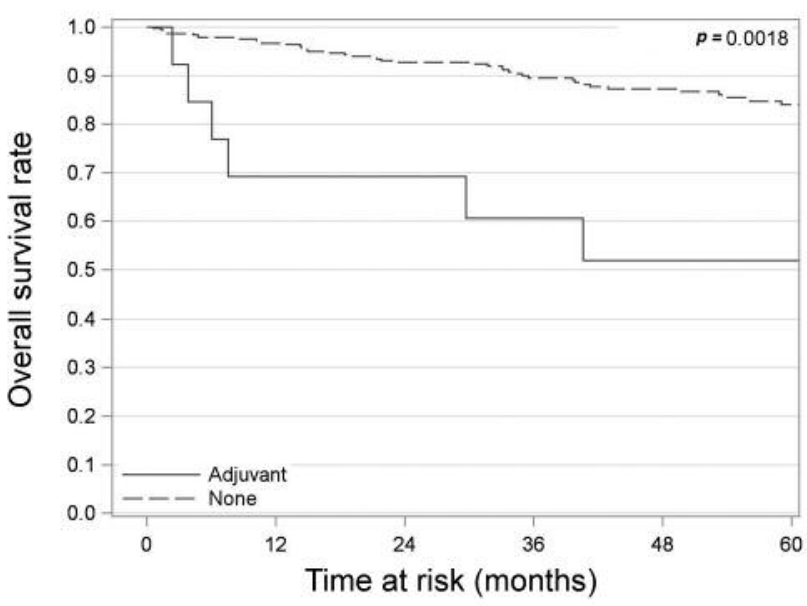

C

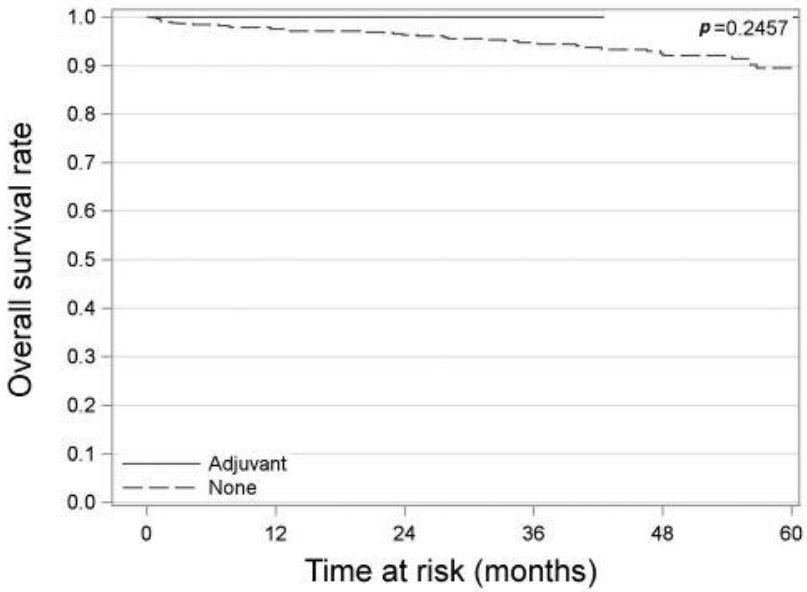

D

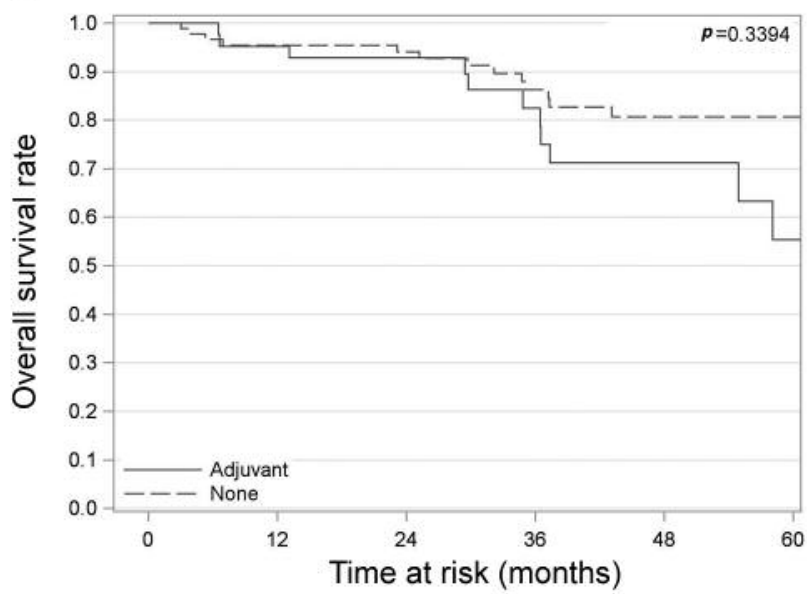

E

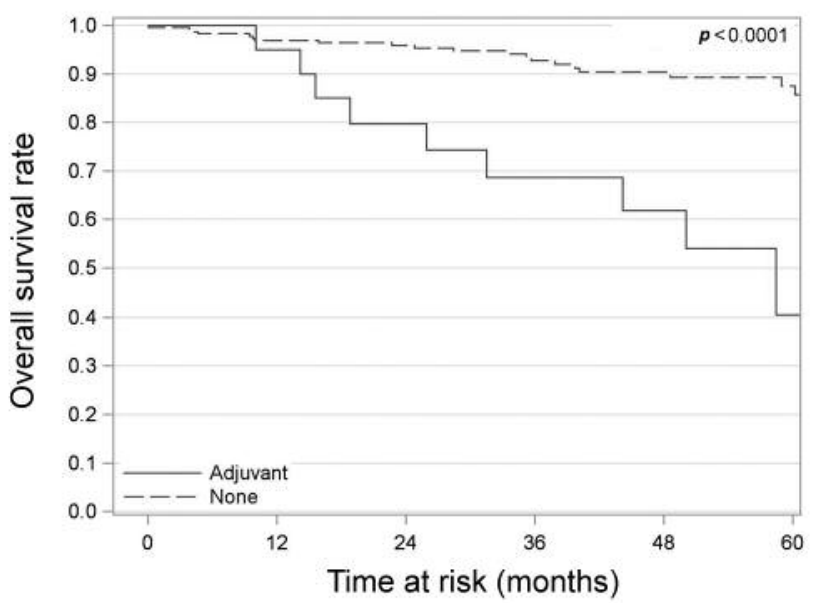

$\mathbf{F}$

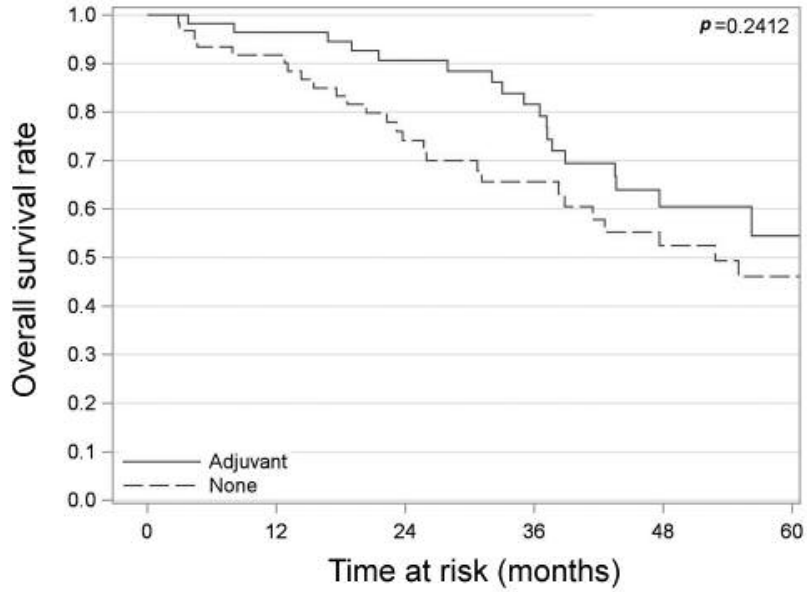

Figure 1. Unadjusted overall survival curves of patients who underwent surgery alone versus surgery followed by adjuvant chemotherapy based on different stages. (A) TC patients with stage I disease. (B) AC patients with stage I disease. (C) TC patients with stage II disease. (D) AC patients with stage II disease. (E) TC patients with stage III disease. $(F)$ AC patients with stage III disease. 
A

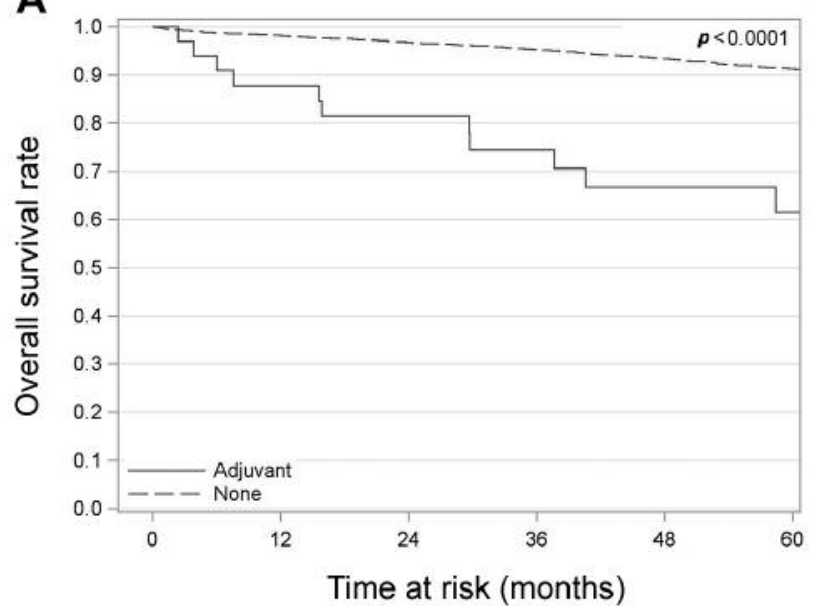

B

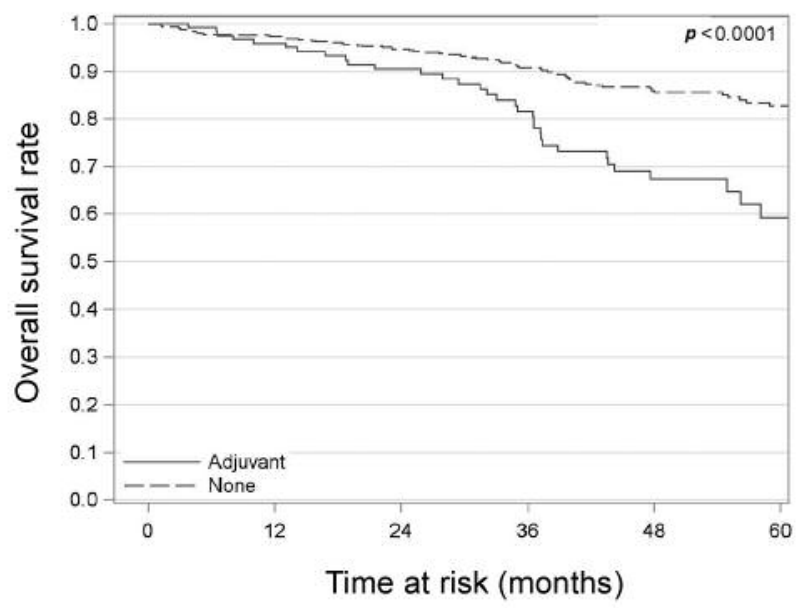

C

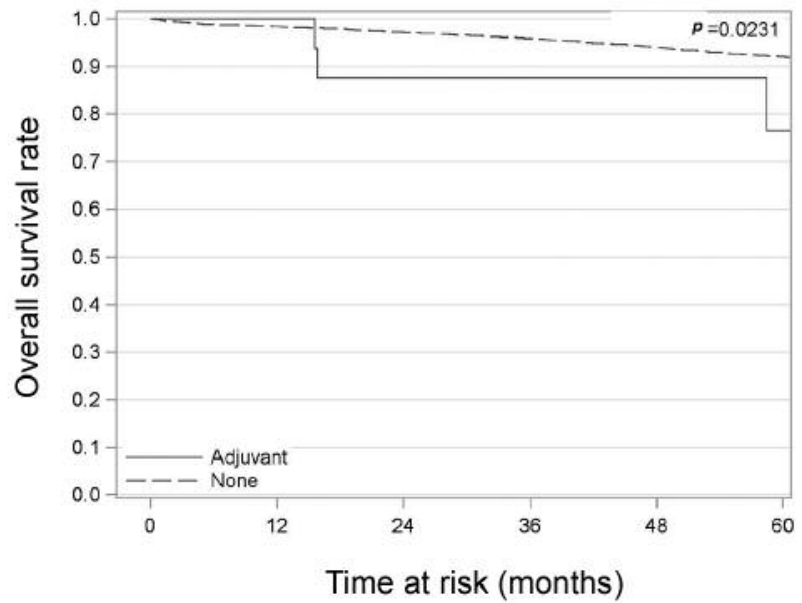

D

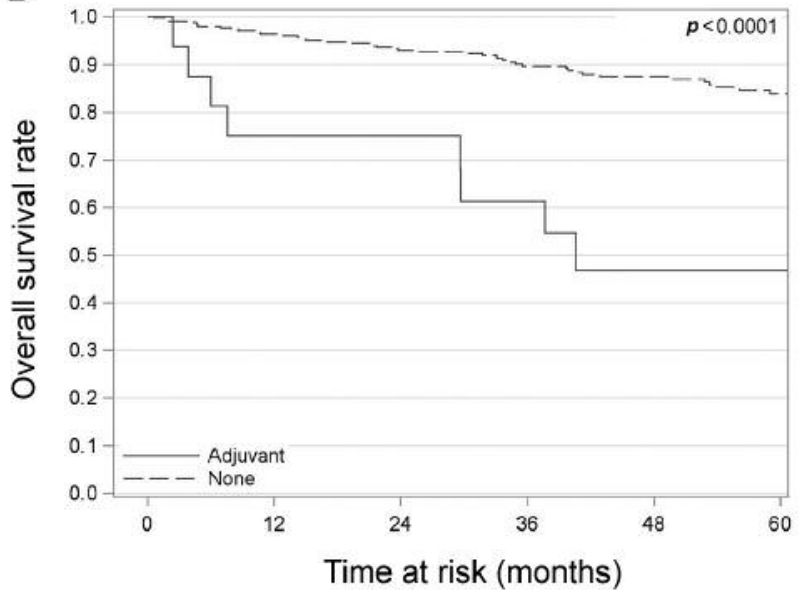

E

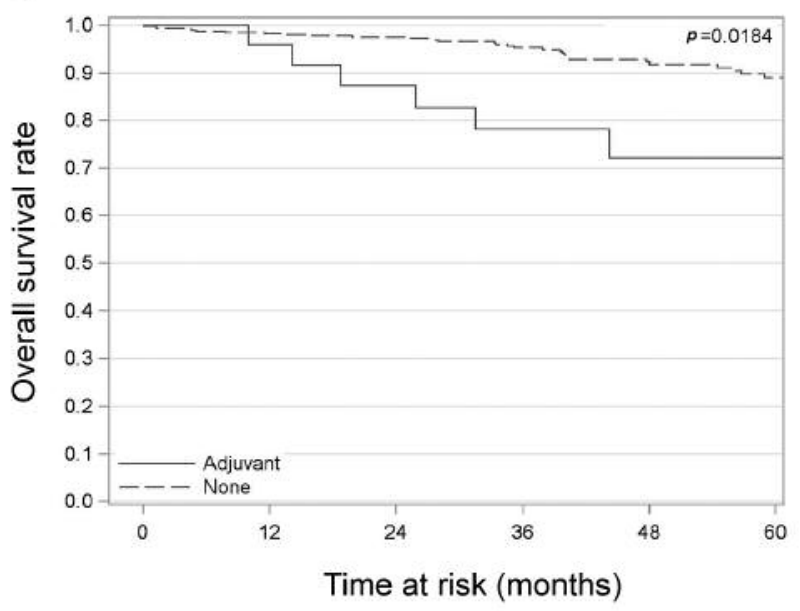

$\mathbf{F}$

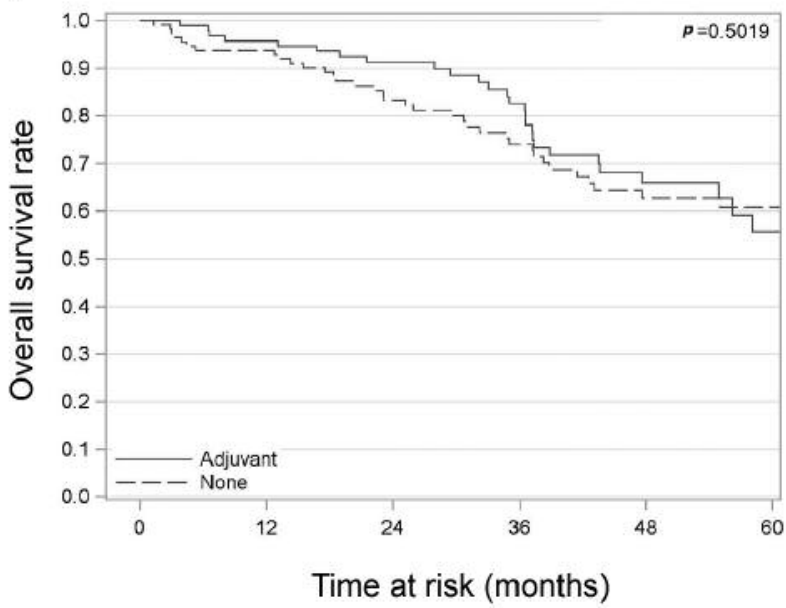

Figure 2. Unadjusted overall survival curves based on patients who underwent surgery alone versus surgery followed by adjuvant chemotherapy based on nodal status. (A) Patients with node-negative disease (TC and AC combined). (B) Patients with node-positive disease (TC and AC combined). (C) TC patients with node-negative disease. (D) AC patients with node-negative disease. (E) TC patients with node-positive disease. (F) AC patients with node-positive disease. 
Table IV. Review of the management of pulmonary neuroendocrine tumor based on different established guidelines.

\begin{tabular}{|c|c|c|c|c|c|c|}
\hline $\begin{array}{l}\text { AJCC } \\
\text { staging }\end{array}$ & $\mathrm{NCCN}$ & NANETS & ENETS & ESMO & $\begin{array}{l}\text { NCDB (2004-2014) } \\
\text { outcomes }\end{array}$ & Comments \\
\hline Stage I & $\begin{array}{c}\text { TC - surgery } \\
\text { alone } \\
\text { AC - surgery } \\
\text { alone }\end{array}$ & $\begin{array}{l}\mathrm{TC}-\text { no adjuvant } \\
\text { recommendations } \\
\mathrm{AC}-\text { no adjuvant } \\
\text { recommendations }\end{array}$ & $\begin{array}{l}\text { TC - surgery } \\
\text { alone } \\
\text { AC - surgery } \\
\text { alone }\end{array}$ & $\begin{array}{l}\mathrm{TC}-\text { no adjuvant } \\
\text { recommendations } \\
\mathrm{AC}-\text { no adjuvant } \\
\text { recommendations }\end{array}$ & $\begin{array}{c}\mathrm{TC}-\mathrm{S} v s . \mathrm{S}+\mathrm{CT} \\
5 \text {-year OS } \\
92 \% \text { ss. } 92 \%(p=0.31) \\
\mathrm{AC}-\mathrm{S} v s . \mathrm{S}+\mathrm{CT} \\
5 \text {-year OS } \\
84 \% \text { vs. } 52 \%(p<0.01)\end{array}$ & $\begin{array}{l}\text { Adjuvant CT did not lead } \\
\text { to significant OS difference } \\
\text { in TC probably because } \\
\text { very few patients got } \\
\text { adjuvant CT, while it was } \\
\text { rather harmful in AC patients }\end{array}$ \\
\hline Stage II & $\begin{array}{c}\text { TC - surgery } \\
\text { alone } \\
\text { AC - surgery } \\
\text { alone }\end{array}$ & $\begin{array}{l}\mathrm{TC}-\text { no adjuvant } \\
\text { recommendations } \\
\mathrm{AC}-\text { no adjuvant } \\
\text { recommendations }\end{array}$ & $\begin{array}{l}\mathrm{TC} \text { - surgery } \\
\text { alone } \\
\mathrm{AC} \text { - surgery } \\
\text { alone }\end{array}$ & $\begin{array}{l}\mathrm{TC}-\text { no adjuvant } \\
\text { recommendations } \\
\mathrm{AC}-\text { no adjuvant } \\
\text { recommendations }\end{array}$ & $\begin{array}{c}\text { TC }-\mathrm{S} v s . \mathrm{S}+\mathrm{CT} \\
5 \text {-year OS } \\
90 \% \text { vs. } 100 \%(p=0.25) \\
\mathrm{AC}-\mathrm{S} v s . \mathrm{S}+\mathrm{CT} \\
5 \text {-year OS } \\
81 \% \text { vs. } 55 \%(p=0.34)\end{array}$ & $\begin{array}{l}\text { Non-significant } p \text {-value } \\
\text { in TC and AC patient } \\
\text { population, again because } \\
\text { of few patients in the } \\
\text { adjuvant CT arm }\end{array}$ \\
\hline Stage III & $\begin{array}{c}\text { TC - surgery } \\
\text { alone } \\
\text { AC - surgery } \\
+/- \text { CT/RT }\end{array}$ & $\begin{array}{l}\mathrm{TC}-\text { no adjuvant } \\
\text { recommendations } \\
\mathrm{AC}-\text { no adjuvant } \\
\text { recommendations }\end{array}$ & $\begin{array}{c}\text { TC - surgery } \\
\text { alone } \\
\text { AC - surgery } \\
\text { followed by } \\
\text { chemotherapy for } \\
\text { positive lymph } \\
\text { nodes disease }\end{array}$ & $\begin{array}{l}\mathrm{TC}-\text { no adjuvant } \\
\text { recommendations } \\
\mathrm{AC}-\text { no adjuvant } \\
\text { recommendations }\end{array}$ & $\begin{array}{c}\mathrm{TC}-\mathrm{S} v s . \mathrm{S}+\mathrm{CT} \\
5 \text {-year OS } \\
88 \% \text { vs. } 41 \%(p<0.01) \\
\text { AC }-\mathrm{S} \text { vs. S+CT } \\
5 \text {-year OS } \\
46 \% \text { vs. } 54 \%(p=0.24)\end{array}$ & $\begin{array}{l}\text { For TC patients, adjuvant } \\
\text { chemo is potentially } \\
\text { harmful } \\
\text { For AC patients, adjuvant } \\
\text { chemotherapy led to } \\
\text { a trend towards } \\
\text { benefit in our study. }\end{array}$ \\
\hline
\end{tabular}

S: Surgery; CT: chemotherapy; RT: radiation therapy.

radiation in ACs (19). On the other hand, ENETS recommends considering adjuvant treatment in AC patients with positive lymph nodes and no adjuvant therapy for TC patients (20). In our analysis, patients with node-positive AC, did not benefit significantly from adjuvant chemotherapy.

Table IV highlights essential differences that exist amongst different guidelines based on different stages. The table also highlights our NCDB retrospective analysis, which is more in-line with the NCCN guidelines. For Stage I/II TC, a total of 25 patients received adjuvant chemotherapy in comparison to 4,425 patients treated with surgery alone, as surgery is considered the standard of care. Therefore, results are not significant for these groups. Similarly, the results for AC stage II $(p=0.34)$ and stage III $(p=0.24)$ are not significant, given the low number of patients.

Retrospective studies have evaluated the benefit of adjuvant chemotherapy in TC (from years 1998-2006) and AC (from years 2006-2011) patients based on their nodal status. In both TC and AC, it was concluded that adjuvant chemotherapy does not confer any survival advantage (16, 17). Our results are similar to what has been demonstrated in the past, as highlighted in Figure 2. An additional benefit from adjuvant chemotherapy was not observed in either node-negative or node-positive ACs or TCs. Additionally, this NCDB analysis looked into the same patient population in different AJCC stages, and no difference in OS or a more inferior OS was found with the addition of adjuvant chemotherapy.

Pulmonary NETs are a unique tumor type. In locally advanced disease, somatostatin analogs (octreotide and lanreotide) have demonstrated a progression-free survival (PFS) benefit $(21,22)$. Also, a combination of octreotide and everolimus, a mTOR inhibitor, has shown promising PFS benefit as well (23-25). Recently approved peptide receptor radionucleotide therapy (PRRT) has also shown a PFS advantage in metastatic gastroenteropancreatic and lung NET patients $(26,27)$. Since these therapies have shown promising results in advanced stage pulmonary NETs, they may also have a role in the adjuvant setting; however, no clinical trials are currently looking into that.

To date, this is the first retrospective study, which evaluated the role of adjuvant chemotherapy in pulmonary NET patients in different stages. However, this study has several limitations. Firstly, it has the inherent limitations of a retrospective study like misclassification bias. Despite the standardized data reporting, like all database analyses, this study could also be affected by the coding error. Secondly, the reason for administering adjuvant chemotherapy was not available, and therefore, a possibility of selection bias cannot be excluded. Thirdly, due to the rarity of this disease, AC cohort in this study was relatively small, which led to some of the statistically insignificant results. Finally, details of adjuvant therapy were not available in the database. 
In conclusion, pulmonary NETs are a rare set of tumors. There is a paucity of randomized studies, which makes treatment challenging. Surgery has been the mainstay of treatment with no consensus on adjuvant therapy. We showed that adjuvant chemotherapy does not add to OS, but is rather associated with inferior OS in some cases. TC patients tend to do better with surgery alone, even in higher stages and node-positive disease. Similarly, in the early stage and nodenegative AC patients, adjuvant chemotherapy may be rather harmful. In stage III and node-positive AC patients, adjuvant chemotherapy may confer some OS benefit, but our results were not statistically significant. In this era of personalized cancer treatment, translational studies should be conducted to understand the biological characteristics of these rare tumors, contributing to differences in the outcomes. Such studies may unveil molecular subgroups, which could benefit from adjuvant treatment.

\section{Conflicts of Interest}

Rohit Gosain, Adrienne Groman, Sai Yendamuri, and Renuka Iyer have no conflicts of interest to declare. Sarbajit Mukherjee - Board of Directors: Esophageal Cancer Action Network (voluntary), Research funding: National Comprehensive Cancer Network (paid to the institute), Panel member: National Comprehensive Cancer Network.

\section{Authors' Contributions}

Rohit Gosain - evaluated the data and performed the analysis, wrote the manuscript, reviewed the manuscript before submission; Adrienne Groman - collected the data and performed the analysis, reviewed the manuscript before submission; Sai Yendamuri verified the data and analysis, edited the manuscript, reviewed the manuscript before submission; Renuka Iyer - verified the data and analysis, edited the manuscript, reviewed the manuscript before submission; Sarbajit Mukherjee - evaluated the data and performed the analysis, reviewed the manuscript before submission.

\section{References}

1 Noel-Savina E and Descourt R: Focus on treatment of lung carcinoid tumor. OncoTargets Ther 6: 1533-1537, 2013. PMID: 24187503. DOI: $10.2147 /$ OTT.S32464

2 Gosain R, Mukherjee S, Yendamuri SS and Iyer R: Management of typical and atypical pulmonary carcinoids based on different established guidelines. Cancers (Basel) 10(12), 2018. PMID: 30545054. DOI: $10.3390 /$ cancers 10120510

3 Yao JC, Hassan M, Phan A, Dagohoy C, Leary C, Mares JE, Abdalla EK, Fleming JB, Vauthey JN, Rashid A and Evans DB: One hundred years after "carcinoid": Epidemiology of and prognostic factors for neuroendocrine tumors in 35,825 cases in the United States. J Clin Oncol 26(18): 3063-3072, 2008. PMID: 18565894. DOI: $10.1200 / J C O .2007 .15 .4377$

4 Travis WD, Brambilla E, Burke AP, Marx A and Nicholson AG: WHO Classification of tumours of the lung, pleura, thymus and heart. Fourth edition. IARC Publications, Lyon, France, pp. 63$77,2015$.
5 Travis WD: Pathology and diagnosis of neuroendocrine tumors: lung neuroendocrine. Thorac Surg Clin 24: 257-266, 2014. PMID: 25065926. DOI: 10.1016/j.thorsurg.2014.04.001

6 Ferguson MK, Landreneau RJ, Hazelrigg SR, Altorki NK, Naunheim KS, Zwischenberger JB, Kent M and Yim AP: Longterm outcome after resection for bronchial carcinoid tumors. Eur J Cardiothorac Surg 18: 156-161, 2000. PMID: 10925223. DOI: 10.1016/s1010-7940(00)00493-0

$7 \mathrm{Xu}$ Z, Mohile SG, Tejani MA, Becerra AZ, Probst CP, Aquina CT, Hensley BJ, Arsalanizadeh R, Noyes K, Monson JR and Fleming FJ: Poor compliance with adjuvant chemotherapy use associated with poorer survival in patients with rectal cancer: An NCDB analysis. Cancer 123: 52-61, 2017. PMID: 27560162. DOI: $10.1002 /$ cncr.30261

8 Dasari A, Shen C, Halperin D, Zhao B, Zhou S, Xu Y, Shih T and Yao JC: Trends in the incidence, prevalence, and survival outcomes in patients with neuroendocrine tumors in the United States. JAMA Oncol 3: 1335-1342, 2017. PMID: 28448665. DOI: 10.1001/jamaoncol.2017.0589

9 Gustafsson BI, Kidd M, Chan A, Malfertheiner MV and Modlin IM: Bronchopulmonary neuroendocrine tumors. Cancer 113: 521, 2008. PMID: 18473355. DOI: 10.1002/cncr.23542

10 Rekhtman N: Neuroendocrine tumors of the lung- An update. Arch Pathol Lab Med 134(11): 1628-1638, 2010. PMID: 21043816. DOI: $10.1043 / 2009-0583-R A R .1$

11 Gustafsson BI, Kidd M, Chan A, Malfertheiner MV and Modlin IM: Bronchopulmonary neuroendocrine tumors. Cancer 113: 521, 2008. PMID: 18473355. DOI: 10.1002/cncr.23542

12 Modlin IM, Lye KD and Kidd M: A 5-decade analysis of 13,715 carcinoid tumors. Cancer 97(4): 934-959, 2003. PMID: 12569593. DOI: $10.1002 /$ cncr.11105

13 Travis WD, Brambilla E, Müller-Hermelink HK and Harris CC: Pathology and genetics of tumours of the lung, pleura, thymus and heart. WHO Classification of Tumours, 3rd Edition, Volume 10, IARC Publications, Lyon, France, 2004.

14 Travis WD: Advances in neuroendocrine lung tumors. Ann Oncol 21: vii65-71, 2010. PMID: 20943645. DOI: 10.1093/ annonc/mdq380

15 Rea F, Rizzardi G, Zuin A, Marulli G, Nicotra S, Bulf R, Schiavon $\mathrm{M}$ and Sartori F: Outcome and surgical strategy in bronchial carcinoid tumors: single institution experience with 252 patients. Eur J Cardio-thoracic Surg 31(2): 186-191, 2007. PMID: 17140801. DOI: 10.1016/j.ejcts.2006.10.040

16 Nussbaum DP, Speicher PJ, Gulack BC, Hartwig MG, Onaitis MW, D'Amico TA and Berry MF: Defining the role of adjuvant chemotherapy after lobectomy for typical bronchopulmonary carcinoid tumors. Ann Thorac Surg 99(2): 428-434, 2015. PMID: 25499480. DOI: 10.1016/j.athoracsur.2014.08.030

17 Anderson KL, Mulvihill MS, Speicher PJ, Yerokun BA, Gulack BC, Nussbaum DP, Harpole DH, D'Amico TA, Berry MF and Hartwig MG: Adjuvant chemotherapy does not confer superior survival in patients with atypical carcinoid tumors. Ann Thorac Surg 104(4): 1221-1230, 2017. PMID: 28760471. DOI: 10.1016/ j.athoracsur.2017.05.011

18 Fox M, Van Berkel V, Bousamra M, Sloan S and Martin RCG: Surgical management of pulmonary carcinoid tumors: Sublobar resection versus lobectomy. Am J Surg 205(2): 200-208, 2013. PMID: 23063095. DOI: 10.1016/j.amjsurg.2012.05.008

19 NCCN clinical practice guidelines in oncology: neuroendocrine tumors. Version 3.2017. Natl Compr Cancer Netw [Internet]. 
2017; Available from: https://www.nccn.org/professionals/ physician_gls/pdf/neuroendocrine.pdf

20 Pavel M, O'Toole D, Costa F, Capdevila J, Gross D, Kianmanesh R, Krenning E, Knigge U, Salazar R, Pape UF and Öberg K: ENETS consensus guidelines update for the management of distant metastatic disease of intestinal, pancreatic, bronchial neuroendocrine neoplasms (NEN) and NEN of unknown primary site. Neuroendocrinology 103: 172185, 2016. PMID: 26731013. DOI: 10.1159/000443167

21 Rinke A, Wittenberg M, Schade-Brittinger C, Aminossadati B, Ronicke E, Gress TM, Müller HH and Arnold R: Placebocontrolled, double-blind, prospective, randomized study on the effect of octreotide lar in the control of tumor growth in patients with metastatic neuroendocrine midgut tumors (PROMID): Results of long-term survival. Neuroendocrinology 104(1): 2632, 2016. PMID: 26731483. DOI: 10.1159/000443612

22 Caplin ME, Pavel M, Ćwikła JB, Phan AT, Raderer M, Sedláčková E, Cadiot G, Wolin EM, Capdevila J, Wall L, Rindi G, Langley A, Martinez S, Blumberg J and Ruszniewski P: Lanreotide in metastatic enteropancreatic neuroendocrine tumors. N Engl J Med 371(3): 224-233, 2014. PMID: 25014687. DOI: $10.1056 /$ NEJMoa1316158

23 Pavel ME, Hainsworth JD, Baudin E, Peeters M, Hörsch D, Winkler RE, Klimovsky J, Lebwohl D, Jehl V, Wolin EM, Öberg K, Van Cutsem Eand Yao JC: Everolimus plus octreotide longacting repeatable for the treatment of advanced neuroendocrine tumours associated with carcinoid syndrome (RADIANT-2): A randomised, placebo-controlled, phase 3 study. Lancet 378(9808): 2005-2012, 2011. PMID: 22119496. DOI: 10.1016/ S0140-6736(11)61742-X

24 Yao JC, Fazio N, Singh S, Buzzoni R, Carnaghi C, Wolin E, Tomasek J, Raderer M, Lahner H, Voi M, Pacaud LB, Rouyrre N, Sachs C, Valle JW, Fave GD, Van Cutsem E, Tesselaar M, Shimada Y, Oh DY, Strosberg J, Kulke MH and Pavel ME: Everolimus for the treatment of advanced, non-functional neuroendocrine tumours of the lung or gastrointestinal tract (RADIANT-4): A randomised, placebo-controlled, phase 3 study. Lancet 387(10022): 968-977, 2016. PMID: 26703889. DOI: $10.1016 / \mathrm{S} 0140-6736(15) 00817-\mathrm{X}$
25 Yao JC, Phan AT, Chang DZ, Wolff RA, Hess K, Gupta S, Jacobs C, Mares JE, Landgraf AN, Rashid A and MericBernstam F: Efficacy of RAD001 (everolimus) and octreotide LAR in advanced low- to intermediate-grade neuroendocrine tumors: Results of a phase II study. J Clin Oncol 26(26): 43114318, 2008. PMID: 18779618. DOI: 10.1200/JCO.2008.16.7858

26 Strosberg J, El-Haddad G, Wolin E, Hendifar A, Yao J, Chasen B, Mittra E, Kunz PL, Kulke MH, Jacene H, Bushnell D, O'Dorisio TM1, Baum RP1, Kulkarni HR, Caplin M, Lebtahi R, Hobday T, Delpassand E, Van Cutsem E, Benson A, Srirajaskanthan R1, Pavel M, Mora J, Berlin J, Grande E, Reed N, Seregni E, Öberg K, Lopera Sierra M, Santoro P, Thevenet T, Erion JL, Ruszniewski P, Kwekkeboom D and Krenning E; NETTER-1 Trial Investigators: Phase 3 trial of 177Lu-dotatate for midgut neuroendocrine tumors. N Engl J Med 376: 125-135, 2017. PMID: 28076709. DOI: 10.1056/NEJMoa1607427

27 Reubi JC and Waser B: Concomitant expression of several peptide receptors in neuroendocrine tumours: Molecular basis for in vivo multireceptor tumour targeting. Eur J Nucl Med Mol Imaging 30(5): 781-793, 2003. PMID: 12707737. DOI: 10.1007/ s00259-003-1184-3
Received November 4, 2019

Revised November 9, 2019

Accepted November 18, 2019 